\title{
How do Families of Adolescents with Suicidal Ideation Behave?
}

\author{
Como Funcionam as Famílias de Adolescentes com Ideação Suicida?
}

\author{
Maria Gouveia-Pereira*, Sonia Abreu \& Cláudia Martins \\ ISPA - Instituto Universitário, Lisboa, Distrito de Lisboa, Portugal
}

\begin{abstract}
The purpose of this study is to analyze how family systems influence adolescents' suicidal ideation. The participants were 534 adolescents ( $51.1 \%$ female and $48.9 \%$ male), with ages ranging from 14 to 18 years $(M=16.18 ; S D=1.14)$. The instruments used were the following: Family Adaptability and Cohesion Evaluation Scale, Psychological Separation Inventory and Questionnaire of Suicidal Ideation. Results have shown that adolescents with higher suicidal ideation belong to the so-called unbalanced families (with low cohesion and flexibility) and have a conflictual dependence to their parents. On the other hand, adolescents that belong to balanced families revealed lower suicidal ideation. In conclusion, the family's cohesion and flexibility are protective factors against adolescents' suicidal ideation.

Keywords: Adolescence, life cycle, cohesion and family adaptability, suicidal ideation.

Resumo

O objetivo deste estudo é analisar de que forma o funcionamento familiar influencia a ideação suicida na adolescência. Para tal, analisámos a coesão e adaptabilidade familiar, assim como a independência conflitual. Participaram neste estudo 534 adolescentes (51,1\% raparigas e 48,9\% rapazes), com idades compreendidas entre 14 e 18 anos $(M=16,18 ; D P=1,14)$. Os instrumentos utilizados foram: Escala de Adaptabilidade e Coesão Familiar; Inventário Separação Psicológica e Questionário Ideação Suicida. Os resultados mostraram que os adolescentes com maior ideação suicida pertencem a famílias desequilibradas (coesão e adaptabilidade baixa) e têm uma forte dependência conflitual a ambos os pais. Os adolescentes pertencentes a famílias equilibradas revelaram menor ideação suicida. A coesão e a capacidade adaptativa da família são fatores protetores da ideação suicida.

Palavras-chave: Adolescência, ciclo de vida, coesão e adaptabilidade familiar, ideação suicida.
\end{abstract}

\section{Considerations on the Family Life Cycle and Adolescence}

Throughout its life history, the family faces a set of developmental stages (Carter \& McGoldrick, 1988) in which specific tasks are to be performed. This sequence of stages is designated as family life cycle. Based on its different phases, Relvas (1996) proposed a set of stages (that include family with adolescent offspring) during which several issues arise, specific of each step, demanding restructuration, adaptation and transformation, not only of the family system, but also of all its members. The concept of life cycle is useful both from a theoretical and a clinical point of view, since it helps understand the evolutionary process and the moment in which individual and family meet.

The family life cycle is punctuated by moments of change that, although possibly considered as normative

\footnotetext{
* Mailing address: Unidade de Investigação em Psicologia Cognitiva do Desenvolvimento e da Educação, ISPA - IU, Rua Jardim do Tabaco, 34, Lisboa, Portugal 1149-041. E-mail: mpereira@ispa.pt.
}

and transitional periods for the family, are frequently experienced with some tension. These changes can either be intrasystemic (caused by changes within the family) on intersystemic (when a change occurs outside the family), and they force its members to adapt and modify their family interactions. Changes resulting from family life cycles or other unexpected events (e.g., divorce, death of a relative) are considered moments of crisis. As situations of instability and unbalance, moments of crisis bring to light the organization, rules, roles and borders of the family. In this way, these moments of transition and change increase the probability of family dysfunction and the appearance of some symptoms, namely suicidal ideation, in one of its members.

One of the most important stages of the family life cycle is the family with adolescent offspring (Relvas, 1996), since it is a transversal stage to three generations that brings major changes to the family dynamic and structure, and also internal changes to its members. That is to say that at the same time the adolescent experiences physical, emotional and behavioral modifications, there is a change in the parent-child relationship, as well as parents reaching midlife and grandparents reaching old age. For this reason, the life cycle with adolescent offspring is 
considered a period of crisis, but also of transformation and change, both for the adolescent (individual cycle) and the family (family cycle). In this way, individual and family cycles intertwine and are interdependent (Saraceno, 1992), which establishes this period as a potential trigger for developmental problems at these two levels (Abaid, Dell'Aglio, \& Koller, 2010).

Considering that individual and family developmental tasks intertwine, some parents may find it difficult to adapt to new demands, thus hindering the adaptation of the adolescent to the changes he/she must experience in order to achieve autonomy, as well as personal and social identity. On the other hand, if the family already has a history of failure concerning previous developmental tasks, this new task - the adolescence of a child - may evidence greater stress (Mombelli, Costa, Marcon, \& Moura, 2011). In other words, the frail stability of the family system is further threatened. According to Minuchin (1988), that threat is often nullified by the family through a rigid (inflexible) or a chaotic (too flexible) functioning. These types of functioning may be experienced by some families, opening way to the malaise of one (or more) of its members, and, consequently, to the possibility of symptomatic behaviors such as thoughts of death in adolescent children. In the systemic perspective, a symptomatic behavior emerges as a mean to express family dysfunction and psychological malaise, and the symptom of one (or more) family elements has the function of reaching the "balance" of the system. In this sense, suicidal ideation can be regarded as a way to express the need for change, both on an individual and a family level, in order that the family reaches the desired balance and can become a factor of protection.

Based on this problem, this work aims to analyze suicidal behaviors in adolescence, considering two interrelated dimensions: the individual dimension, in which difficulties such as the failure of separation and independence from parents are focused; and the family dimension, both in terms of emotional involvement (cohesion) and in terms of the family's ability to adapt to this new life cycle.

\section{Adolescence and Psychological Separation}

The individual tasks that occur in adolescence, such as the construction of identity and the acquisition of independence, are specific of this stage and detached from those which are inherent in childhood. As for the construction of identity, the adolescent needs to differentiate himself/ herself from parental figures, or, as Bowen (1991) refers, to differentiate from the family ego mass and experiment other forms of being. Laufer (2000) adds that tasks in adolescence are organized in three main cores: (a) change in the relationship with parents; (b) change in the relationship with peers; and (c) formation of sexual identity. It should be noted that dealing successfully with the tasks of adolescence increases the probability of success in later phases.

In adolescence, the psychological separation from parents has been referred by different theoretical approaches as a fundamental task (Blos, 1967; Claes, 1990; Erikson, 1968; Fleming, 1993) which can be acquired through a relational change with parents and with the group of peers. The success of this task demands a shifting movement on the part of the adolescent from the family to the social context, thereby resulting in a progressive investment in the group of peers. However, these relational changes do not imply a rupture in the bond with the parents, but rather a transformation of the relationship that is necessary for the adolescent's successful acquisition of autonomy. In fact, some studies have proven that a rupture of bonds is a risk factor for suicidal behaviors (Pereira, 2011). This process of autonomy is also a major challenge for the family, since it demands changes in the type of interfamily relationships, given that these were, until then, relationships of complete dependency (child/parents). The process of autonomy depends, amongst other factors, on the quality the adolescent acknowledges in the relationship with the parents (Fleming, 2005). By helping the adolescent built his/her autonomy, parents are facilitating his/her assumption of adult roles in the social, relational and affective life. This relational transformation between parents and children implies a flexibilization of boundaries and/or rules, as well as a balanced emotional involvement (contained and supportive), in order that the family mobilizes alternative and adequate functional interactive patterns to this new stage of individual and family life. The nonoccurrence of this transformation may compromise the adolescent's process of autonomy, thus favoring the emergence of symptoms among which suicidal ideation is an example.

According to Dias and Fontaine (2001), psychological separation can be regarded as a necessary condition for the construction of autonomy in a broad sense. Hoffman (1984) too argues that the adolescent's healthy adjustment depends on the capability to psychologically detach himself/herself from the parents, while simultaneously keeping positive family bonds. The process of separation is therefore constructed in a context of progressive redefinition and of transformation of the bonding relationships of the adolescent (Soares \& Campos, 1988), thus denoting a biunique dynamic in which parents and adolescents are deeply involved.

According to Pereira (2011), the factors that most trigger suicidal behavior are conflicts with parents, affective rupture and school problems. Teodoro, Cardoso and Freitas (2009) argued that a healthy relationship with the parents is an important factor to prevent depression amongst children and adolescents. In their studies, depression was negatively correlated with affectivity, and positively with conflict. In this way, affectively deprived and contentious family relationships increase depressive symptoms in adolescence. In a study conducted by Martins and Gouveia-Pereira (2012), adolescents with higher levels of suicidal ideation are those that present lower independence concerning their parents in the conflictual dimension, when compared to those with lower levels of suicidal ideation. The studies of Abaid et al. (2010) point towards the same conclusion. 
Hoffman (1984) conceptualized psychological separation according to four dimensions: emotional independence, functional independence, attitudinal independence and conflictual independence. According to the author, the conflictual dimension refers to the adolescent's independence from negative feelings regarding both parents, such as an excessive sense of guilt, resentment, anxiety, distrust, anger and inhibition. Dias and Fontaine (2001) say that conflictual independence is that which best reflects the successful resolution of the psychological separation from parents. In the same fashion, Santos (2001) refers that the dimension of conflictual independence seems to represent an independent dimension from the other sub-dimensions, while also presenting higher levels of validity, since it is related with several scores of adaptation and psychological wellbeing. For this reason, we will only analyze the dimension of conflictual independence in this study.

\section{Suicide and Suicidal Ideation in Adolescence}

Suicide is a complex phenomenon, originated in multiple factors and for which no linear causality can be verified. For this reason, and for the psychological and emotional implications caused, both individually and for the family, this phenomenon continues to be target of great interest and diverse reflections. In Europe, suicide represents the second leading cause of death of young people between the ages of 15 and 24, preceded only by car accidents. In Portugal, suicide attempts are rather common in adolescence, more frequently amongst girls (World Health Organisation [WHO], 2011).

Suicidal ideation can be defined by thoughts and cognitions about ending one's life, and may go on a hierarchical crescendo, from general thoughts about death to rather serious idealizations about ways to commit suicide (Ferreira \& Castela, 1999; Sampaio, 1991; Saraiva, 1999). Sampaio (2002) argues that suicidal behaviors have an appealable and relational function, that is, they appeal for change in the communication of the family system (meta-communication), by transmitting that something is not right and that it is necessary for changes to occur in the family context. Suicidal behaviors therefore have an ambivalent and relational nature, in the sense that they can be regarded as self-destructive gestures or thoughts, but are simultaneously attempts of communication and appeals for change.

\section{Family (Dys)Function and Suicidal Ideation in Adolescence}

Several authors have suggested a number of family risk factors that can influence suicidal ideation, such as parental psychopathology, low communications levels, high levels of conflict, family violence, death or parental absence, family isolation and even family functioning (Pereira, 2011). Family functioning is understood as the forms of relation- ship the family establishes (or not) between its members, namely the way they organize everyday life, the way they communicate and show affection, and how they are capable of positively overcoming change, among other aspects. As previously mentioned, a family with adolescent offspring is forced to find different interactional patterns from the ones used until the beginning of puberty, which implies the search for alternative patterns from those used until then and the flexibility to mobilize them (Minuchin, 1988).

The psychosocial growth of family elements is possible when the family is an integrated group, in which there is no excessive enmeshment or disengagement (level of cohesion), that is, in which the established emotional links between family members allow, simultaneously, individualization as well as a sense of belonging. As mentioned above, separation and autonomy are basic tasks of this stage, both for the adolescent and the parents (Whitaker \& Bumberry, 1990). However, when the family system is not sufficiently adapted (and permeable to the necessary changes), these tasks fail, thus threatening the family system and allowing the emergence of suicidal symptomatology (Abaid et al., 2010).

$\mathrm{Au}, \mathrm{Lau}$ and Lee (2009), as well as Branco, Wagner and Demarchi (2008), Compton, Thompson and Kaslow (2005), Holtman, Shelmerdine, London and Flisher (2011), Prabhu, Molinari, Bowers and Lomax (2010), and Souza et al. (2010) have demonstrated, in their different studies, that an unbalanced family functioning is associated with suicidal behavior in adolescents. The studies of Abaid et al. (2010), Payne and Range (2001) and Teodoro et al. (2009) have also shown a positive relation between high vulnerability to suicide and low levels of family cohesion (disengaged families) and flexibility within the family (rigid families).

The Circumplex Model of Marital and Family Systems developed by Olson (2000) considers two dimensions cohesion and adaptability - as key dimensions for the functioning of any family system. The dimension of cohesion remits to the emotional links established between family members, as well as to the level of separation or connection each member has with the family. As for the dimension of adaptability, it refers to the capability of the family system to reorganize and to address the stress caused by development or certain situations (Barnes \& Olson, 1985). In this way, the focus of cohesion will be on the way the family system balances the emotional connection and separation between the individual and the family, while the focus of flexibility will be on the way the system balances its stability in the face of change. According to Olson (2000), the conjugation of cohesion and adaptability levels will originate three family types: (a) balanced families, which present a low risk of mental illness (balanced); (b) families of medium mental risk (midrange); and (c) families of high mental risk (unbalanced).

At the level of cohesion, families that are considered balanced have greater functionality, and individuals are capable of being independent from parents while also 
emotionally linked to them; that is not the case for the unbalanced levels. As for the dimension of adaptability/ flexibility, more functional levels reveal a balance between stability and change, as well as a tendency for the family to be stable throughout time. Rigid families, on the other hand, show strictly defined roles and poor flexibility in the enforcement and/or change of family rules, while chaotic families (too flexible) reveal poorly defined roles and scarce reflection in decision-making (Olson, 2000). This model thus departs from the hypothesis that families considered to be balanced (i.e. with central/balanced levels of cohesion and flexibility) will find it easier to appropriately respond to the demands of the life cycle stages, in the sense that they are able to experience the extremes of a dimension for short periods of time, when compared to unbalanced families in one or both dimensions.

Based on what was referred, the aim of this study is to analyze if the way a family functions (at the levels of cohesion and adaptability/flexibility) and the psychological separation of the adolescent (conflictual independence from mother and father, separately) can influence suicidal ideation. In this sense, our hypothesis is that adolescents that belong to families considered to be balanced and with a high level of conflictual independence from mother or father (separately) are those with lower suicidal ideation.

\section{Method}

\section{Participants}

The sample was composed of 534 adolescents from primary ( $9^{\text {th }}$ grade) and secondary school between the ages of 14 and $18(M=16.18 ; S D=1.14)$, of which $51.1 \%$ are female and $48.9 \%$ are male. $75.5 \%$ of the adolescents' parents are married, while $23.9 \%$ are separated. Convenience sampling was selected from the area of Greater Lisbon - Portugal.

\section{Instruments}

Family Adaptability and Cohesion. This scale is based on the Family Adaptability and Cohesion Evaluation Scale (FACES III) developed by Olson, Portner and Lavee (1985) to analyze the previously mentioned Circumplex Model. It is composed of 20 items that refer to the dimensions of cohesion (e.g., "People from my family approve each other's friends") and adaptability/flexibility (e.g., "In my family, parents and children discuss punishments together"). The dimension of family cohesion had the following results: $M=3.50 ; S D=.65$ and $\alpha=.81$; and the dimension of flexibility had these results: $M=3.10 ; S D=$ .58 and $\alpha=.66$. High scores in the scales of cohesion and flexibility indicate balanced systems, while low scores reflect unbalanced systems. From the conjugation of the cohesion and flexibility levels, and according to Olson (2000), we have operationalized families in the following way: balanced, midrange and unbalanced.

Psychological Separation Inventory - Conflictual Independence. This inventory was developed by Hoffman
(1984) and adapted by Santos (2001) to a sample of Portuguese adolescents. In whole, the inventory has 88 items ( 44 for each parental figure) and 4 subscales of independence: emotional, attitudinal, conflictual and functional. Considering the aim of this study, and as mentioned above, we have only considered the subscale of conflictual independence, which is composed of 22 items, 11 for each parent (e.g., "I get annoyed when my father/my mother judges me.") For this subscale, these were the results: $M_{\text {mother }}=2.79 ; S D_{\text {mother }}$ $=.74$ and $\alpha_{\text {mother }}=.85 ; M_{\text {father }}=2.70 ; S D_{\text {father }}=.74$ and $\alpha_{\text {father }}$ $=.86$. In order to counterbalance the order effect, we have first applied to half the subjects the scale regarding the mother, and then the scale regarding the father, while the opposite was done with the other half.

Suicidal Ideation. This scale was adapted by Ferreira and Castela (1999) and is composed of 30 items (e.g., "I thought of killing myself" and "I thought of death"). For this measure, the results were: $M=1.88 ; S D=.97$ and $\alpha$ $=.97$.

\section{Procedures}

In a personal contact with the board of a primary and secondary school of Greater Lisbon, we have presented the goals of this study, explained the instruments used and provided an informed consent form directed to the institution. In cooperation with the vice-president of the governing board and after obtaining the consent of the participant adolescents, 14 classes were selected by convenience sampling. The surveys were applied by one of the investigators during school time (approximately 30 minutes), without the presence of teachers in the classrooms of the school. Participants were granted confidentiality and anonymity, and assured of the availability to clarify any doubt during or after filling the surveys. They were provided with the contact and address of the hospitals closer to their homes, to which they could go in case of need.

\section{Results}

Initially, we analyzed if there were statistically significant differences regarding suicidal ideation between the children of married and of separated (23.9\%) parents through a Student's $t$-test. The results showed that there were no significant differences between the adolescents of these two groups.

Olson's (2000) conjugation of cohesion and flexibility levels resulted in a subdivision in three family types (balanced, midrange and unbalanced). In Table 1, the distribution of subjects in the sample according to the family type they belong to can be analyzed.

With the purpose of analyzing our main hypothesis, we have verified if there were statistically significant differences regarding suicidal ideation according to family type (balanced, midrange, unbalanced) and degree of conflictual independence (high or low) from mother and father (separately). We created two two-way ANOVAs. 
Table 1

Percentages of Adolescents Belonging to the Different Family Types

\begin{tabular}{cc}
\hline Family Types & $\%$ \\
\hline Balanced & $24.6 \%$ \\
Midrange & $49.5 \%$ \\
Unbalanced & $25.9 \%$ \\
\hline
\end{tabular}

Results have shown that there are no interaction effects between the independent variables (family type and conflictual independence from mother and father) in suicidal ideation. There were, however, two key effects in these variables. Concerning the main effect family type, there were statistically significant differences in suicidal ideation in relation to the three family types (Table 2). The results of the Post Hoc Tests (Turkey) have shown that there are statistically significant differences in suicidal ideation between the group of adolescents that belong to families considered unbalanced $(M=2.33 ; S D=1.15)$ and those that belong to families considered balanced $(M=1.61 ; S D=.67)$ and midrange $(M=1.80 ; S D=.92)$. According to these results, we have verified that adolescents who belong to families considered balanced and midrange present lower suicidal ideation.

Table 2

Means of Individuals Concerning the Main Effects of Variables Family Type and Conflictual Independence from Mother in Suicidal Ideation

\begin{tabular}{cccc}
\hline & & Mean & Standard Deviation \\
\hline Family Type & Balanced & 1.61 & .67 \\
& Midrange & 1.80 & .92 \\
Unbalanced & 2.33 & 1.15 \\
Conflictual Independence - Mother & {$[F(2.533)=16.74 ; p<0.001]$} & & \\
& High & 1.73 & .87 \\
& Low & 2.04 & 1.03 \\
\hline
\end{tabular}

Table 3

Means of Individuals Concerning the Main Effects of Variables Family Type and Conflictual Independence from Father in Suicidal Ideation

\begin{tabular}{cccc}
\hline & & Mean & Standard Deviation \\
\hline \multirow{2}{*}{ Family Type } & Balanced & 1.61 & .67 \\
& Midrange & 1.80 & .92 \\
& Unbalanced & 2.33 & 1.15 \\
Conflictual Independence - Father & {$[F(2.527)=19.84 ; p=.001]$} & & .88 \\
& High & 1.74 & 1.03
\end{tabular}


Regarding the main effect of the variable conflictual independence from the mother, we verified that adolescents who belong to the group with high levels of conflictual independence presented lower levels of suicidal ideation $(M=1.73 ; S D=.87)$ when compared to those that belong to the group with low levels of conflictual independence $(M=2.04 ; S D=1.03$; Table 2).

As for the results regarding the influence of family type (balanced, midrange and unbalanced) and the level of conflictual independence (high or low) from the father, we have verified a similar result pattern to that above (Table 3 ), that is, adolescents with high conflictual independence from the father presented lower levels of suicidal ideation when compared to those with low conflictual independence.

\section{Discussion}

\section{Type of Family Functioning and Suicidal Ideation}

The results obtained regarding the type of family functioning confirm our main hypothesis (i.e., the family type in which adolescents are inserted has an influence on their suicidal ideation). We have then noted that families considered to be unbalanced consist of adolescents with higher levels of suicidal ideation when compared to those from midrange and balanced families. In this line of thought, unbalanced families do not express the ability to change their relational patters nor the capacity to reach balance between emotional proximity and separation amongst themselves, as well as between stability and change. These families are most likely blocked to the desirable changes of the family life cycle with adolescent offspring, an aspect reflected in their children's suicidal ideation. This study also shows that balanced and midrange families appear to be more adapted, consequently managing to have healthier dynamics and appropriately addressing situations, since adolescents belonging to these families revealed lower levels of suicidal ideation.

By regarding suicidal ideation as a precursor of more severe behaviors, we can assume that these results are in line with the studies of Au et al. (2009), Branco et al. (2008), Compton et al. (2005), Prabhu et al. (2010) and Souza et al. (2010), in which families with higher levels of dysfunction are those whose adolescent children present higher levels of suicidal ideation, as opposed to adolescents with lower levels of suicidal ideation, who belong to balanced and midrange families.

On of the possible explanations for these results can be associated with the fact that adolescents who belong to balanced families acknowledge the existence of a strong connection between its members, simultaneously having a flexible family dynamic with ability to renegotiate. This acknowledgement leads to satisfaction and psychological wellbeing. Therefore, we can say that adolescents have the need for strong links, while simultaneously requiring the recognition of some flexibility to renegotiate the relationship with their parents. In this way, they deduce that the family system to which they belong has the ability to endure the necessary changes of the period they are crossing - adolescence.

However, it should be noted that, as Minuchin (1988) argued, the term dysfunctionality should be reserved to families that, facing a time of crisis and/or change, increase their rigidness and resist the exploration of alternatives, while being constricted to extremes. This is not the case for families that experience extremes in certain moments of their life, but use synergies to change and transform the way of (dys)functioning that was until then familiar and known to them.

\section{Conflictual Independence and Suicidal Ideation}

The analysis of results regarding conflictual independence showed that adolescents with high conflictual independence from their mother or father were the ones that presented lower levels of suicidal ideation, when compared to those with low conflictual independence. We have concluded that the more difficulties the adolescents reveal in dealing with psychological separation from parents (i.e., the more dependent at the conflictual level they are, the higher are their levels of suicidal ideation). According to these results, the adolescents from our sample that presented higher conflictual independence (more independence from negative feelings towards their parents, such as an excessive sense of guilt, resentment, anxiety, distrust, anger and inhibition), have also revealed a greater psychological detachment that allowed them to build their own autonomy.

Our results are consistent with the studies of Peixoto, Saraiva and Sampaio (2006), Teodoro et al. (2009), and Tomori, Kienhorst, de Wilde and Van den Bout (2001), in which the occurrence of suicidal ideation in young people is related to conflicts with the mother and/or father. Psychological independence allows the adolescent to achieve the process of autonomy with less difficulty and more effectively. On the contrary, a lower level of independence from the mother or the father makes the process more difficult, thus potentiating higher levels of suicidal ideation. We defend that the adolescent's psychological separation does not imply a rupture of bonds with the parents, but an interactional transformation towards interdependency and relational co-evolution. Therefore, we can say that suicidal ideation is a way to express the failure of the adolescent's autonomy process, that is, one of the fundamental tasks of adolescence.

Indeed, the way conflict is managed and elaborated in the family system will determine either the evolution of the autonomy process (Relvas, 1996) or, in alternative, the emergence of a symptom. In order for the conflict to cause a change in the system, there must be a secure bond from adolescents to parents and vice versa. Despite the essential aspect of the conflict and the inevitability of change in the family's structure and functioning, the attainment of autonomy by adolescents is only fulfilled when they feel 
loved and accepted by their parents. In families with a predominantly hostile and devaluing relationship, the process of autonomy is compromised, originating an impasse in the normal development of the adolescent (Fleming, 2005), or even the permanence of conflict. Watzlawick, Beavin and Jackson (1967) referred to suicidal behavior as a way of communicating the suffering the adolescent finds himself/herself in, which may be caused by family crisis or by symbiotic relationships that allow neither autonomy nor the resolution of emerging conflicts. Sampaio (1991) even suggested that the suicidal gesture is a paradoxical attempt to change family relationships.

Our results have shown that suicidal ideation can be triggered by individual and relational variables, given that an analysis only at an individual level would be like looking at a single piece of the puzzle, thus limiting the understanding of the phenomenon and its respective therapeutic intervention. It seems relevant to continue the analysis of suicidal ideation in a family dynamic perspective, since the understanding and prevention of suicide includes obtaining information about the precursors of suicidal behavior in nonclinical populations. In this regard we agree with Prabhu et al. (2010), as their model of suicide prevention establishes family participation in the adolescent's therapeutic process as being fundamental.

Throughout this study, we became aware of some limitations that brought to light the pertinence of further investigation regarding certain aspects. One of these limitations was the fact that this work was developed taking into account the adolescent's perspective, thus providing access to the point of view of only one member of the family system. It would be important to analyze family functioning from the father's and the mother's point of view, as well as to study types of communication within the family system in order to analyze if they influence this process and suicidal ideation.

Suicidal behavior as a way to express suffering can arise in the form of thoughts about death, possibly moving towards an authentic dying wish and following suicide attempt, then materialized in the adolescent's death (acting-out). It is vital to pursue investigation in the sense of understanding the protection factors for suicidal behavior - what leads some adolescents to go through a suicidal act and others not.

All variables and systems the adolescents are inserted in (school, peer group, among others) can provide support and protection for a healthy development, but they can also be regarded as risk factors for suicidal behavior. We hope this study may awaken some reflections within the context of clinical exercise, namely in the intervention of families with adolescent offspring, both with and without suicidal ideation. The quality of family functioning is an important variable which cannot be neglected in the analysis of this problem or in the work done with young adolescents, since it can be a protection factor for suicidal ideation in adolescence.

\section{References}

Abaid, J., Dell'Aglio, D., \& Koller, S. (2010). Preditores de sintomas depressivos em crianças e adolescentes institucionalizados. Universitas Psychologica, 9(1), 199-212.

$\mathrm{Au}$, A., Lau, S., \& Lee, M. (2009). Suicide ideation and depression: The moderation effects of family cohesion and social self-concept. Adolescence, 44(176), 851-868.

Barnes, H., \& Olson, D. (1985). Parent-adolescent communication and the circumplex model. Child Development, 56 , 438-447.

Blos, P. (1967). The second individuation process of adolescence. Psychoanalytic Study of the Child, 22, 162-186.

Bowen, M. (1991). De la familia al individuo: la diferenciación del si mismo en el sistema familiar. Buenos Aires, Argentina: Paidós.

Branco, B., Wagner, A., \& Demarchi, K. (2008). Adolescentes infratores: Rede social e funcionamento familiar. Psicologia: Reflexão e Crítica, 21(1), 125-132.

Carter, B., \& McGoldrick, M. (Eds.). (1988). The changing family life cycle. New York: Gardner Press.

Claes, M. (1990). Os problemas da adolescência. Lisboa, Portugal: Verbo.

Compton, M. T., Thompon, N. J., \& Kaslow, N. J. (2005). Social enviroment factors associated with suicide attempt among low-income African Americans: The protective role of family relationships and social support. Social Psychiatry and Psychiatric Epidemiology, 40(3), 175-185.

Dias, G., \& Fontaine, A. (2001). Tarefas desenvolvimentais e bem-estar de jovens universitários. Lisboa, Portugal: Calouste Gulbenkian Foundation.

Erikson, E. H. (1968). Identity: Youth and crisis. New York: Norton.

Ferreira, J. A., \& Castela, M. C. (1999). Questionário de ideação suicida (Q.I.S). In M. Simões, M. Gonçalves, \& L. Almeida (Eds.), Testes e provas psicológicas em Portugal (Vol. 2, pp. 123-130). Braga, Portugal: Sistemas Humanos e Organizacionais.

Fleming, M. (1993). Adolescência e Autonomia. Porto, Portugal: Afrontamento.

Fleming, M. (2005). Entre o medo e o desejo de crescer. Psicologia da Adolescência. Porto, Portugal: Afrontamento.

Hoffman, J. A. (1984). Psychological separation of late adolescents from their parents. Journal of Counseling Psychology, 31, 170-178.

Holtman, Z., Shelmerdine, S., London, L., \& Flisher, A. (2011). Suicide in a poor rural community in the Western Cape, South Africa: Experiences of five suicide attempters and their families. South African Journal of Psychology, 41(3), 300-309.

Laufer, M. (2000). O adolescente suicida. Lisboa, Portugal: Climepsi.

Martins, C., \& Gouveia-Pereira, M. (2012). A autonomia psicológica na adolescência e ideias de morte. Trabalho apresentado no $9^{\circ}$ Congresso Nacional de Psicologia da Saúde, Aveiro, Portugal.

Minuchin, S. (1988). Famílias, funcionamento e tratamento. Porto Alegre, RS: Artes Médicas.

Mombelli, M., Costa, J., Marcon, S., \& Moura, C. (2011). Estrutura e suporte familiar como fatores de risco de stress infântil. Estudos de Psicologia (Campinas), 28(3), 327-335.

Olson, D. H. (2000). Circumplex model of marital and family systems. Journal of Family Therapy, 22, 144-167. 
Olson, D. H., Portner, J., \& Lavee, Y. (1985). FACES III. St. Paul, MN: University of Minnesota, Department of Family Science.

Payne, B. J., \& Range, L. M. (2001). Family enviroment, depression, attitudes toward life and death and suicidality in young adults. Hattiesburg, MS: University of Southern Mississipi.

Peixoto, B., Saraiva, C., \& Sampaio, D. (2006). Comportamentos suicidários em Portugal. Coimbra, Portugal: Sociedade Portuguesa de Suicidologia.

Pereira, C. (2011). Risco suicidário em jovens: avaliaçãoo e intervençãoo em crise. Revista do Serviço de Psiquiatria Prof. Doutor Fernando da Fonseca, 9(1), 11-23.

Prabhu, S., Molinari, V., Bowers, T., \& Lomax, J. (2010). Role of the family in suicide prevention: In attachment and family systems perspective. Bulletin of the Menninger Clinic, 74(4), 301-327.

Relvas, P. (1996). O ciclo vital da família. Perspectiva sistémica. Porto, Portugal: Afrontamento.

Sampaio, D. (1991). Ninguém morre sozinho. Lisboa, Portugal: Caminho.

Sampaio, D. (2002). Intervenção familiar em adolescentes suicidas. Psycologica, 31, 85-92.

Santos, P. J. (2001). Psychological separation inventory: Revisão da investigação e análise factorial com uma amostra de adolescentes. Psiquiatria Clínica, 22(3), 287-304.

Saraceno, C. (1992). Sociologia da família. Lisboa, Portugal: Estampa.

Saraiva, C. (1999). Para-suicídio. Coimbra, Portugal: Quarteto.

Soares, I., \& Campos, B. (1988). Vinculação e autonomia na relação do adolescente com os pais. Cadernos de Consulta Psicológica, 4, 57-64.

Souza, L., Ores, L., Oliveira, G., Cruzeiro, A., Silva, R., Pinheiro, R., \& Horta, B. (2010). Ideação suicida na adolescência: Prevalência e fatores associados. Journal Brasileiro de Psiquiatria, 59(4), 286-292.

Teodoro, M., Cardoso, B., \& Freitas, A. (2009). Afetividade e conflito familiar e sua relação com a depressão em crianças e adolescentes. Psicologia: Reflexão e Crítica, 23(2), 324-333.

Tomori, M., Kienhorst, C., de Wilde, E., \& Van den Bout, J. (2001). Suicidal behaviour and family factors among Dutch and Slovenian high school students: A comparison. Acta Psychiatrica Scandinavica, 104(3), 198-203.

Watzlawick, P., Beavin, J., \& Jackson, D. (1967). Pragmática da comunicação humana. São Paulo, SP: Cultrix.

Whitaker, C., \& Bumberry, W. (1990). Dançando com a família. Uma abordagem simbólico experiencial. Porto Alegre, RS: Artes Médicas.

World Health Organisation. (2011). Suicide prevention and special programmes. Retrieved October, 2012, from http:// www.who.int/mental_health/prevention/suicide/suicideprevent/en/index.html 